\title{
Research on the Effectiveness of Technical Indicators with the Volume
}

\author{
Gang LI \\ College of Management \\ Shanghai University \\ Shanghai, China \\ Email: llihoude@hotmail.com
}

\author{
Jin Zhu \\ College of Management \\ Shanghai University \\ Shanghai, China \\ Email: zhujin0205@gmail.com
}

\begin{abstract}
The paper researches on the effectiveness of technical indicator with the volume by choosing the volumeweighted moving average (VWMA) which consists of the simple moving average (MA) and volume based on the 2139 stocks from January 1, 2003 to January 1, 2013 in China's Ashare market. There are four criteria to evaluate the volumeweighted moving average: sensitivity, reliability, risk and benefits. Comparing the performance of VWMA and MA in the sample stocks, there are several advantages by adding volume information to technical indicators: issue more trading signals, increase the proportion of profitable trading, reduce the average drawdown, and improve investment returns.
\end{abstract}

Keywords- volume; MA; VWMA

\section{INTRODUCTION}

Technical analysis indicators are applied extensively in stock market and frequently utilized as tools to forecast the trend of the stock price. But the results are often not satisfactory when investors use the technical analysis indicators which are only related to the stock price and not involve volume to forecast the trends. Volume is a number that investors willing to buy the stock at a price and shows the force of rose or fell. The volume is also on behalf of the support and pressure in stock market. Therefore the relationship between price and volume in stock market is always a hotspot in the financial sector and has been studied by a large number of scholars. In the paper, we research on the effectiveness of technical indicator with the volume on the basis of the conclusions about the relationship between price and volume and hope that the conclusions can be as the reference basis for the technical analyst when they study the stocks..

\section{LiterATURE REVIEW}

Price and volume are intuitive and timely to describe the market trading. And the relationship between price and volume is the most fundamental and important entry point for being aware and understanding of the stock, stock trading and stock market.

In foreign, studying the relationship between price and volume can be traced back to Osborne (1959) [1] that he illustrates the price movement is a diffusion process through establishing a model. In the model, variance depends on the number of transactions, and it suggests that there is a positive correlation between volume and the absolute value of the changes in price. Afterwards, the volume-price relation has attracted the attention of quite a number of theoretical researchers, which greatly enriched the theory of financial market microstructure. Godfrey, Granger, and Morgenstern (1964) [2] found that there is a positive correlation between daily volume and stock daily price height difference. Crouch (1970)[3] found that there is a positive correlation between the daily trading volume and the absolute value of the daily stock price changes whatever the study object is a market index or a stock. Clark (1973) [4] found a positive correlation between the square of price changes and the total volume with the daily data in a cotton futures market. Epps and Epps (1976) [5] found a positive correlation between the sample variance of price movements and volume with the transaction data of 20 stocks. Morgan (1976) [6] researched 51 stocks with every four days and monthly data, and found that the variance of all these changes in the stock price is positively related to volume. Westerfield (1977) [7] also found the relationship with 315 stocks. Jain and John (1985) [8] found the approximate relationship with the hourly market index data.

In recent years, Chinese scholars began to learn the theories and analytical tools of Western scholars, and have done a lot of analysis about the volume-price relation in China's stock market. Chen Yiling, Song Fengming (2000) [9] have done a multi-level empirically research about the relationship between the price changes and trading volume in China's stock market by using a random sample of 31 stocks. The conclusion is: there is a linear positive correlation between the daily trading volume and the absolute value of price changes; and it is an asymmetric relationship between price and volume in China's stock market. Wu Chongfeng, Wang Chengwei and Wu Wenfeng (2002) [10] empirically test the linear and nonlinear Granger causality relationship between volume and price of China's stock market and showed that there exits linear Granger causality from stock return to volume and bi-directional nonlinear Granger causality between these time series. Li Fujun, Da Qingli (2005) [11] analyzed the dynamic relationship between the price return and volume by using the evidence from China's stock market. The results showed that the positive relationship and bi-direction linear Granger causality are maintained between price returns and volume. Guo Liang, Zhou Weixing (2010) [12] performed an empirical analysis of the volume-price relation in China's stock market at microscopic level using high-frequency data and found that the price variation and trading volume are correlated and the volume-price curve is a nonlinear convex function.

In summary, domestic and foreign scholars had done a lot of research on the relationship between price and volume. A large number of research results indicated the existence of a certain relationship between price and volume, and it 
provides a sufficient basis for the next research. Many technical analysts know the existence of the complementary relationship between price and volume, and trading volume is the fuel to maintain the price movements. The most important is to increase the volume if sound and strong price trend want to maintain, at least not to reduce. When the trading volume reduced and the market fuel will reduce, then the original price trends is inevitable unable to maintain for a long time. So it can effectively circumvent the misjudgment for trading point caused by various factors of technical indicators when technical analyzers analysis the price trends by using technical indicators with volume. Therefore the paper hopes to explore whether the trading points showed by the technical indicators are more objectively and effectively when the volume is considered.

\section{EMPIRICAL ANALYSES}

\section{A. Method Introduction}

In the field of technical analysis, a very important factor is the volume to judge whether a market is a bull or bear market. In a bull market, price increases with increasing volume and it is dangerous that price increases without increasing volume. In an adjustment market, volume must be reduced. In a bear market, price reduces with increasing volume and price increase with reducing volume. Therefore, the volume should be taken into account when investors are designing an effectively moving average. Investors can endow the high-volume trading day with great weights; on the contrary, endow the low-volume trading day with the small weight.

Obviously, there may be more successful transactions and can gain more profit based on the price trend and the changes in volume compared to use a single technical indicators. The paper researches a new moving average which is composed of a commonly used technical indicator and volume and can be called volume-weighted moving average (VWMA).

The calculation method of VWMA is that each trading day's closing price is weighted with the proportion of the trading volume accounted for the total volume of the given period.

$$
W M A=\frac{\sum_{l=1} R_{l} \times C_{l}}{\sum_{l=1}^{n} R_{l}}
$$

In which, VWMA is the volume-weighted moving average, $\mathrm{V} \_\mathrm{i}$ is the volume on $\mathrm{i}$ day, $\mathrm{C} \_\mathrm{i}$ is the closing price on i day. Weight is the day's trading volume. Investors can endow the high-volume trading day with greater weights; on the contrary, endow the low-volume trading day with the small weight.

The paper chooses four criteria to evaluate the volumeweighted moving average: sensitivity, reliability, risk and benefits. Sensitivity measures whether VWMA sends more signal than MA. Reliability measures whether VWMA is as reliably as MA. Risk measures whether VWMA can reduce the average drawdown and benefits measures whether VWMA can improve investment returns in transactions.

\section{B. Sample Selection}

The template is used to format your paper and style the text. All margins, column widths, line spaces, and text fonts are prescribed; please do not alter them. You may note peculiarities. For example, the head margin in this template measures proportionately more than is customary. This measurement and others are deliberate, using specifications that anticipate your paper as one part of the entire proceedings, and not as an independent document. Please do not revise any of the current designations.

\section{Comparison of VWMA and MA}

In order to verify whether the performance of the technical indicators is better or not after adding the volume information, the paper examines and compares these two trading methods. The first method is to use a simple moving average (unweight) with five days and twenty days. The second method is to use a volume-weighted moving average with five days and twenty days. Both of these methods regard the intersection of the 5-day and 20-day moving average line as a buy or sell signal. That is, it is a buy signal when average 5 through 10 on average; similarly it is a sell signal when average 10 through 5 on average. In empirical analysis, the initial amounts is one million RMB, and when the methods issue a "buy signal", then buy in full; when the methods issue a "sell signal", then sell all of the shares.

1) Sensitivity

If the volume leads to price, it should changes and issues the buy or sells signals in advance before the price appears a significance change. Therefore, compared VWMA with MA, VWMA can identify the trends faster, issues the buy or sells signals faster and help investors to enter or exit the market earlier.

For the sample stocks, VWMA issues more signal in 1589 stocks (Figure 1, A); Ma issues more signal only in 276 stocks(Figure 1, B); Both of these technical indicators issue the same number of signals in the remaining 274 stocks(Figure 1, C), as shown in Figure 1. On the whole, MA issues 56007 trading signals in all sample stocks; VWMA issues 60171 trading signals in all sample stocks and increases $6.9 \%$ in sensitivity, as shown in Figure 2.

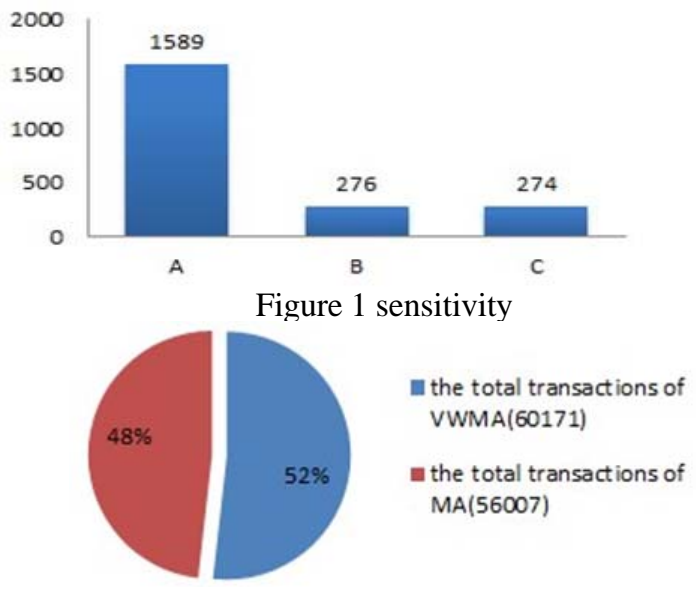

Figure 2 comparison of the total transactions 


\section{2) Reliability}

Of course, it is good that a technical indicator is faster to issue the buy or sells signals. And it doesn't particularly difficult to do. In order to make a moving average issue signals faster, it's just to shorten the cycle of calculating the average. However it sacrifices the reliability to issue more signals. It is difficult to choose because the reliability and sensitivity are equally important.

However, according to the previous estimation, it can improve the reliability and sensitivity at the same time after adding the volume. High volume can confirm the validity of the price changes. In addition, when it appears difference between the trading volume and price changes, the signals issuing by volume-based indicators will be relatively slow. In order to test the reliability, the paper compares the ratio of profitable transaction of VWMA and MA.

After the test, we found out that VWMA shows more reliability than MA. The ratio of profitable transaction of VWMA and MA accounts for $42.17 \%$ and $40.47 \%$. There are 1256 stocks whose the winning percentage is higher by using VWMA than MA in sample stocks (Figure 3, A); There are only 791 stocks whose the winning percentage is higher by using MA than VWMA (Figure 3, B); the winning percentage of the remaining 92 stocks are equal(Figure 3, C), as shown in Figure 3. Meanwhile, there are 1773 profit shares and 366 loss shares and the proportion of the profit shares accounting for $82.9 \%$ by using VWMA; there are 1641 profit shares and 498 loss shares and the proportion of the profit shares accounting for $76.7 \%$ by using $\mathrm{MA}$, as shown in Figure 4.

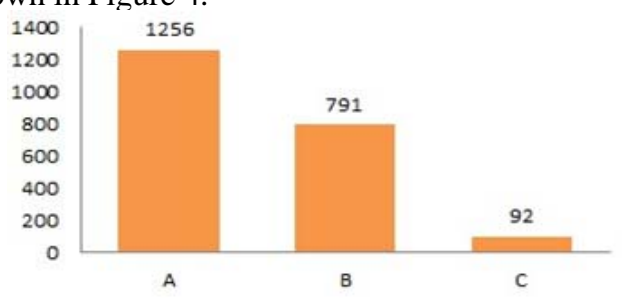

Figure 3 reliability

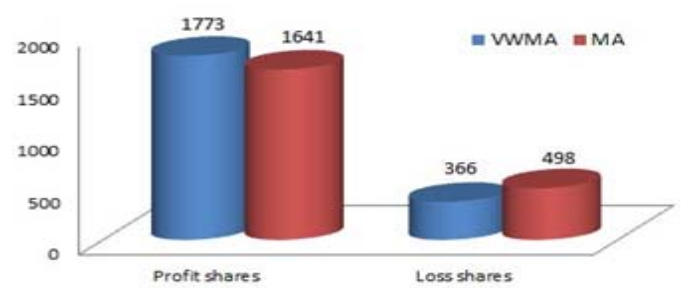

Figure 4 comparison of the profit shares and loss shares 3) Risk

No matter which methods used to trading, it is very important to manage the risk of falling stock prices. In order to test whether the volume-weighted moving average can reduce the risk, the average drawdown is used to measure the risk in this paper. The average drawdown is the average amount of the loss of all losing transactions. This data is used to calculate the potential loss under the normal conditions of a transaction method.
In the test, using the Simple Moving Average: 498 stocks loss, accounting for $23.3 \%$ of the sample stocks, the average drawdown for each stock is 193,161.64 RMB (Figure 5, A); using the Volume-weighted Moving Average: 366 stocks loss, accounting for $17.7 \%$ of the sample stocks, the average drawdown for each stock is 159259.85 RMB (Figure 5, B), 33901.79 RMB less than the MA. Then, we test these 498 stocks using the VWMA which are loss by using the MA and found out that: the average drawdown of 416 stocks reduced, accounting for $83.5 \%$, and the average drawdown of each stock dropped to 67,795 RMB (Figure 5, C),decreased by 125366.64 RMB, as shown in Figure 5.

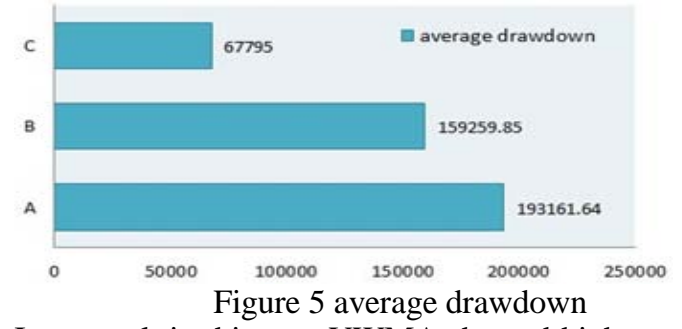

In general, in this test, VWMA showed higher reliability than MA; especially in reducing the average drawdown, the effect is particularly significant. Based on the results, it can be found that it is helpful for investors to trade by using the average price indicators in which the volume is taken into account.

\section{4) Benefits}

From these three aspects what are the sensitivity, reliability, and risk, we can found out that the volume information is valid. But it not involves the most important evaluation criteria which also is most concerned by investors so far. That is benefits. So, which on earth is MA or VWMA that can bring a higher return on investment for investors?

In the sample stocks tested, there are 1484 stocks whose annual return are more by using VWMA than MA, accounting for $69 \%$ of all stocks; there are only 1484 stocks whose annual return is less by using VWMA than MA, accounting for $31 \%$ of all stocks, as shown in Figure 6.

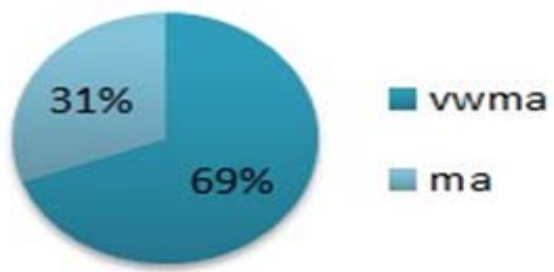

Figure 6 the proportion of the more annual return At the same time, in the test, using the MA: there are 1641 stocks which are profitable, accounting for $76.7 \%$ of the sample stocks; using the VWMA: there are 1773 stocks which are profitable, accounting for $82.9 \%$ of the sample stocks. Respectively using these two methods, we get the average profit, the average profit margin and the average annual return about the profit stocks, as shown in Table 1. 
Table 1 Compare the benefits of MA and VWMA

\begin{tabular}{|c|c|c|c|}
\hline & $\begin{array}{c}\text { Average } \\
\text { profit(RMB) }\end{array}$ & $\begin{array}{c}\text { Average } \\
\text { profit } \\
\text { margin }\end{array}$ & $\begin{array}{c}\text { Average } \\
\text { annual } \\
\text { return }\end{array}$ \\
\hline VWMA & 1100124 & $110.01 \%$ & $25.89 \%$ \\
\hline MA & 1019545 & $102.02 \%$ & $23.68 \%$ \\
\hline $\begin{array}{c}\text { The } \\
\text { difference }\end{array}$ & 80579 & $8.99 \%$ & $2.21 \%$ \\
\hline
\end{tabular}

What can be drawn from table 1 is that investors can get more average profits, higher average profit margin and more average annual return by using VWMA than MA. So we can conclude that investors can get a higher return on investment when they take into account the volume.

\section{CONCLUSIONS}

In the paper, we choose 2139 stocks which are in China's A-share market as the sample, and the research period is from January 1, 2003 to January 1, 2013. In the empirical analysis, we select the simple moving average which is a commonly used technical analysis indicator and the volumeweighted moving average for the study and evaluate the performance of MA and VWMA in the sample stocks with four criteria: sensitivity, reliability, risk and benefits. Then after taking into account the volume, it can be found: the sensitivity of the indicators improved, the reliability enhanced, investment risks and losses reduced, the investment return increased. Therefore, we can draw the conclusion combined with the study: the application of the technical indicators which take into account the volume information is more effective than pure price index in stock market.

\section{REFERENCES}

[1] [1] M.F.M.Osborne. Brownian Motion in the Stock Market[J].Operations Research,1959, 7:145-173.

[2] [2]Michael D.Godfrey,Clive W.J.Granger,Oskar Morgenstern.The Random-Walk Hypothesis of Stock Market Behavior[J].Kyklos,1964,17:1-30.

[3] [3]Robert L.Crouch.The Volume of Transactions and Price Changes on the New York Stock Exchange[J].Financial Analysts Journal,1970,26:104-109.

[4] [4]Peter K.Clark.A subordinated stochastic process model with finite variance for speculative prices[J].Econometrica,1973,41:135-155.

[5] [5]Thomas W.Epps,Mary Lee Epps.The stochastic dependence of security price changes and transaction vovolumes:Implications for mixture -of-distribution hypothesis[J].Econometrica,1976,44:305-321.

[6] [6]I.G.Morgan.Stock Prices and Heteroskedasticity[J].The Journal of Business, 1976,49:496-508.

[7] [7]Janice Moulton Westerfield.An Examination of Foreign Exchange Risk Under Fixed and Floating Rate Regimes[J].Journal of International Economics,1977,7:181-200.

[8] [8]P Jain,GH Joh.The Dependence Between Hourly Prices and Trading Volume[J].Journal of Financial and Quantitative Analysis,1988,23:269-283.

[9] [9]Chen Yiling,Song Fengming.An empirical study on the relationship between price changes and trading volume in China stock market[J]. Journal of Management Sciences In China, 2000,3(2):6268.

[10] [10]Wang Chengwei,Wu Chongfeng.Linear and nonlinear Granger causality test of stock price-volume relation:Evidences from Chinese markets[J].Journal of Management Sciences In China, 2002,5(4):7-12.

[11] [11]Li Fujun,Da Qingli.Volatility between volume and price returns: evidence from Chinese stock markets [J].Journal of Southeast University (Natural Science Edition),2005,35(2):308-310.

[12] [12]Guo Liang,Zhou Weixing.An Empirical Analysis of the VolumePrice Relation Using High-Frequency Data in the Chinese Stock Market[J].Chinese Journal of Management, 2010,7(8):1242-1247. 